\title{
PERANCANGAN SISTEM INFORMASI GEOGRAFIS PEMETAAN DAERAH RAWAN TANAH LONGSOR, MITIGASI DAN MANAJEMEN BENCANA DI KABUPATEN BANJARNEGARA
}

\author{
Tedy Setiadi \\ Program Studi Teknik Informatika UniversitasAhmad Dahlan Yogyakarta
}

\begin{abstract}
ABSTRAK
Background: Banjarnegara district is an area prone to landslides. Current disaster management system landslide is not yet available, while for mapping landslide area already exists, but in the form of a conventional map. As a result, the information is static, difficult updated and does not provide a lot of information that people need because it is not accessible by the public.Metode yang

Methods : Using sequential linear methods (waterfall) include systems analysis and design stages of the system. In the analysis of the classification system is to determine user needs and specifications. In system design includes the design DFD to model the process, ERD to model the data, as well as interface design (prototype).

Results : This research yield the system requirements specification, design and prototyping process DFD. The features of which include mapping of landslide-prone areas, mitigation and disaster management. System is equipped with an early warning activities to deliver information in the form of results predicted weather/climate. While the disaster management system in the form of the ability to display the number of refugees, the number of refugee shelters, layoutlayout and post evacuation needs of each post
\end{abstract}

Keywords : GIS, Landslides, Mitigation, Disaster Management

\section{PENDAHULUAN}

Kabupaten Banjarnegara merupakan salah satu kabupaten yang ada di Jawa Tengah. Ibukotanya adalah Banjarnegara. Secara astronomi, Kabupaten Banjarnegara terletak di antara $7^{\circ} 12^{\prime}-7^{\circ} 31^{\prime}$ Lintang Selatan dan $109^{\circ} 29^{\prime}-109^{\circ}$ 45'50" Bujur Timur. Luas Wilayah Kabupaten Banjarnegara adalah 106.970,997 ha atau $3,10 \%$ dari luas seluruh Wilayah Provinsi Jawa Tengah. Kabupaten ini berbatasan dengan Kabupaten Pekalongan dan Kabupaten Batang di Utara, Kabupaten Wonosobo di Timur, Kabupaten Kebumen di Selatan, dan Kabupaten Banyumas dan Kabupaten Purbalingga di Barat.

Berdasarkan bentuk tata alam dan geografisnya kabupaten ini dibagi menjadi 3 wilayah, yaitu zona utara adalah kawasan pegunungan yang merupakan bagian dari Dataran Tinggi Dieng, Pegunungan Serayu Utara. Daerah ini memiliki relief yang curam dan bergelombang. Di perbatasan dengan Kabupaten Pekalongan dan Kabupaten Batang terdapat beberapa puncak, seperti Gunung Rogojembangan dan Gunung Prahu. Kemudian zona tengah, merupakan zona Depresi Serayu yang cukup subur dan yang ketiga adalah zona selatan merupakan bagian dari Pegunungan Serayu, merupakan daerah pegunungan yang berelief curam.

Bentuk geografis dan topografi seperti di atas Kabupaten Banjarnegara termasuk daerah rawan tanah longsor. Pemerintah dan masyarakat harus tahu dan tanggap dalam hal ini, sehingga dapat lebih waspada. Yang selanjutnya dapat meminimalkan korban apabila sewaktu-waktu bencana tersebut datang. Mitigasi 
bencana longsor pada prinsipnya bertujuan untuk meminimumkan dampak bencana tersebut. Untuk itu kegiatan early warning (peringatan dini) bencana menjadi sangat penting. Peringatan dini dapat dilakukan antara lain melalui prediksi cuaca/iklim sebagai salah satu faktor yang menentukan bencana longsor.

Pemerintah Kabupaten dalam penanganan manajemen bencana tanah longsor saat ini masih dilakukan secara manual dengan bantuan software yang ada seperti MS Excel dan MS Word tanpa dilakukan optimalisasi. Sehingga kebutuhan informasi dan pelaporan yang cepat dan akurat sulit untuk didapatkan. Sedangkan untuk pemetaan daerah tanah longsor saat ini sudah ada namun dalam bentuk peta konvensional yang tentu saja susah diakses masyarakat luas. Oleh karena itu perlu dibuat suatu software khusus agar pemetaan daerah rawan tanah longsor dan manajemen bencana dapat dilakukan dengan lebih baik, efektif dan efisien

Sistem Informasi Geografis (SIG) merupakan suatu alat yang dapat digunakan untuk mengelola (input, manajemen, proses, dan output) data spasial atau data yang bereferensi geografis ${ }^{1}$.

Beberapa kemampuan dari SIG:

a. Memetakan Letak.

Kemampuan ini memungkinkan seseorang untuk mencari dimana letak suatu daerah, benda, atau lainnya di permukaan bumi. Fungsi ini dapat digunakan seperti untuk mencari lokasi rumah, mencari rute jalan, mencari tempat-tempat penting dan lainnya yang ada di peta.

b. Memetakan Kuantitas.

Dengan melihat penyebaran kuantitas tersebut dapat mencari tempattempat yang sesuai dengan kriteria yang diinginkan dan digunakan untuk pengambilan keputusan, ataupun juga untuk mencari hubungan dari masingmasing tempat tersebut

c. Memetakan Kerapatan.

Dengan pemetaan kerapatan dapat dengan mudah membagi konsentrasi daerah kedalam uni-unit yang lebih mudah untuk dipahami dan seragam, misalkan dengan memberikan warna yang berbeda pada daerah-daerah yang memiliki konsentrasi.tertentu. Pemetaan kerapatan ini biasanya digunakan untuk data-data yang berjumlah besar seperti sensus penduduk.

d. Memetakan Apa yang Ada di Luar dan di Dalam Suatu Area.

SIG digunakan juga untuk memonitor apa yang terjadi dan keputusan apa yang akan diambil dengan memetakan apa yang ada pada suatu area dan apa yang ada diluar area.

Secara umum, terdapat dua jenis fungsi analisis yaitu fungsi analisis spasial dan fungsi analisis atribut. ${ }^{2}$

a. Fungsi analisis atribut terdiri dari operasi dasar sistem pengelolaan basisdata (DBMS) dan perluasannya :

1. Operasi dasar basisdata yang mencakup :

a. Membuat basisdata baru

b. Menghapus basisdata

c. Membuat tabel basisdata

d. Menghapus tabel basisdata

e. Mengubah, meng-edit dan menghapus data yang ada di tabel

2. Perluasan operasi basisdata :

a. Membaca dan menulis basisdata dalam sistem basisdata yang lain (export dan import).

b. Dapat berkomunikasi dengan sistem basisdata yang lain.

c. Dapat menggunakan bahasa basisdata standart SQL (structured query language) 
b. Fungsi analisis spasial terdiri dari :

1. Klasifikasi (reclassify) : fungsi ini mengklasifikasikan kembali suatu data spasial (atau atribut) menjadi data spasial yang baru dengan menggunakan kriteria tertentu..

2. Network (jaringan) : fungsi ini merujuk data spasial titik-titik (point) atau garis-garis (lines) sebagai suatu jaringan yang tidak terpisahkan

3. Overlay : fungsi ini menghasilkan data spasial baru dari minimal dua data spasial yang menjadi masukkannya.

4. Buffering : fungsi ini akan menghasilkan data spasial baru yang berbentuk poligon atau zone dengan jarak tertentu dari data spasial yang menjadi masukannya.

5. 3D analysis : fungsi ini terdiri adari sub-sub fungsi yang berhubungan dengan presentasi data spasial dalam ruang 3 dimensi.

6. Digital Image Processing : fungsi ini dimiliki oleh perangkat SIG yang berbasiskan raster. Karena data spasial permukaan bumi banyak didapat dari perekaman data satelit yang berformat raster, maka banyak SIG raster yang juga dilengkapi dengan fungsi analisis ini.

Tanah longsor adalah suatu peristiwa geologi di mana terjadi pergerakan tanah seperti jatuhnya bebatuan atau gumpalan besar tanah. Peristiwa tanah longsor atau dikenal sebagai gerakan massa tanah, batuan atau kombinasinya, sering terjadi pada lereng-lereng alam atau buatan dan sebenarnya merupakan fenomena alam yaitu alam mencari keseimbangan baru akibat adanya gangguan atau faktor yang mempengaruhinya dan menyebabkan terjadinya pengurangan kuat geser serta peningkatan tegangan geser tanah. ${ }^{3}$

Para ilmuwan mengkategorikan tanah longsor sebagai salah satu bencana geologis yang paling bisa diperkirakan. Parameter untuk memantau kemungkinan terjadinya perpindahan massa tanah dalam jumlah besar dalam bentuk longsor, yaitu ${ }^{4}$ :

1) Keretakan pada tanah ujud yang biasa ditemui pada banyak kasus. Bentuknya bisa konsentris (terpusat seperti lingkaran) atau parallel dan lebarnya beberapa centimeter dengan panjang beberapa meter, sehingga bisa dibedakan dari retakan biasa. Formasi retakan dan ukurannya yang makin lebar merupakan parameter ukur umum semakin dekatnya waktu longsor.

2) Penampakan runtuhnya bagian-bagian tanah dalam jumlah besar. Selanjutnya kejadian longsor di satu tempat menjadi parameter kawasan tanah longsor lebih luas lagi. Perubahan-perubahan ini seiring waktu mengindikasikan dua hal : kerusakan lingkungan (misalnya : penggundulan hutan dan perubahan cuaca secara ekstrim) dan menjadi tanda-tanda penting bahwa telah terjadi penurunan kualitas landskap dan ekosistem.

Penyebab utama kejadian ini adalah gravitasi yang mempengaruhi suatu lereng yang curam, namun ada pula faktor-faktor lainnya yang turut berpengaruh, diantaranya:

1) Erosi yang disebabkan sungai-sungai atau gelombang laut yang menciptakan lereng-lereng yang terlalu curam.

2) Geomorfologi (kemiringan daerah)

Kontribusi pengurangan kuat geser tanah pada lereng alam yang mengalami longsor disebabkan terhadap friksi yang terjadi dalam tanah, pelServicesan tanah, pengaruh gempa, geomorfologi (kemiringan daerah).

3) Curah Hujan dan Intensitas Hujan

Curah hujan yang tinggi dan intensitas hujan tinggi atau sedang, dengan durasi yang lama di awal musim hujan atau menjelang akhir musim hujan 
menimbulkan perubahan parameter tanah yang berkaitan dengan pengurangan kuat gesernya.

4) Jenis Tanah dan Jenis Batuan

Kondisi geologi antara lain jenis tanah, tekstur (komposisi) dari tanah pembentuk lereng sangat berpengaruh terjadinya longsoran, misalnya sensivitas sifat-sifat tanah lempung, adanya IServicesan tanah shale, loess, pasir lepas dan bahan organik. Bentuk butiran tanah (bulat ataupun tajam) berpengaruh pada batuan pengurangan kuat geser dapat diakibatkan oleh adanya

diskontinuitas, sifat kekakuan, arah bedding, joint, orientasi, lerang, derajat sementasi batuan misalnya konglomerat, pasir, breksi dan lain-lain.

5) Gempa Bumi menyebabkan tekanan yang mengakibatkan longsornya lerenglereng yang lemah.

6) Gunung BerService menciptakan simpanan debu yang lengang, hujan lebat dan aliran debu-debu.

7) Getaran dari mesin, lalu lintas, penggunaan bahan-bahan peledak dan bahkan petir

8) Berat yang terlalu berlebihan, misalnya dari berkumpulnya hujan dan salju.

Tanah longsor sendiri merupakan gejala alam yang terjadi di sekitar kawasan pegunungan. Semakin curam kemiringan lereng satu kawasan, semakin besar kemungkinan terjadi longsor. Semua material bumi pada lereng memiliki sebuah "sudut mengaso" atau sudut di mana material ini akan tetap stabil. Bebatuan kering akan tetap di tempatnya hingga kemiringan 30 derajat, akan tetService tanah yang basah akan mulai meluncur jika sudut lereng lebih dari 1 atau 2 saja. $^{5}$

Longsor terjadi saat Servicesan bumi paling atas dan bebatuan terlepas dari bagian utama gunung atau bukit. Hal ini biasanya terjadi karena curah hujan yang tinggi, gempa bumi atau letusan gunung Service. Dalam beberapa kasus, penyebab pastinya tidak diketahui. Longsor dapat terjadi karena patahan alami dan karena faktor cuaca pada tanah dan bebatuan. Kasus ini terutama pada iklim lembab dan panas seperti di Indonesia. Ketika longsor berlangsung IServicesan teratas bumi mulai meluncur deras pada lereng dan mengambil momentum dalam luncuran ini, sehingga luncuran akan semakin cepat (sampai sekitar 30 meter/detik). Volume yang besar dari luncuran tanah dan lumpur inilah yang merusak rumah-rumah, menghancurkan bangunan yang kokoh dan menyapu manusia dalam hitungan detik. ${ }^{6}$

\section{METODE}

Penelitian ini menggunakan sebagian metode sekuensial linier dalam pembangunan perangkat lunaknya. Tahapannya mencakup :

\section{Analisis Kebutuhan Sistem}

Kegiatan yang dilakukan pada tahap ini adalah menganalisis kebutuhan sistem pengelolaan pariwisata di Kabupaten Banjarnegara. Kegiatan analisis mengacu pada data-data hasil wawancara dan observasi di Bappeda Kabupaten Banjarnegara. Hasil dari analisis kebutuhan sistem ini dijadikan sebagai dasar untuk menentukan spesifikasi sistem informasi pariwisata yang akan dikembangkan. 


\section{Perancangan Sistem}

Kegiatan yang dilakukan pada tahap ini adalah merancang DFD (Data Flow Diagram), merancang basis data, proses digitasi dan merancang antarmuka (user interface).

1. Perancangan DFD dilakukan dengan menggunakan Power Designer 15.

Perancangan ini untuk menggambarkan aliran data dari sistem informasi geografis. Entitas eksternal dari sistem ini adalah masyarakat, petugas dan Kepala Bappeda.

2. Perancangan basis data dilakukan dengan Power Designer 15. Basis data dirancang agar mampu untuk mengelola data peta longsor, jalur evakuasi, peta lokasi pengungsian, peringatan bahaya dan berita

3. Untuk merancang antarmuka (prototipe) digunakan Axure Pro 5. Perancangan antarmuka dibuat untuk bagian pengunjungbagian bagian administrator, dan manajer.

\section{HASIL PENELITIAN DAN PEMBAHASAN}

\section{A. Hasil Penelitian}

\section{a. Analisis Kebutuhan Sistem}

Spesifikasi kebutuhan sistem yang diingnkan berupa sistem informasi yang berbasis web dilengkapi fungsi google maps untuk pengolahan data spasial. Adapun pengguna sistem terbagi tiga yakni administrator sistem, manajer (kepala BNPBD), serta pengguna umum (masyarakat). yang dapat mengakses via web.

Adapun spesifikasi kebutuhan pengguna sistem sebagai berikut :

1. Pengguna umum

a. Dapat melihat peta kerawanan tanah longsor dan daerah berdasarkan tingkat kerawanan tanah longsor rendah, sedang dan tinggi.

b. Dapat melihat tipe-tipe longsor serta informasi ciri-ciri, penyebab dan pencegahan tanah longsor berdasarkan tipe longsorannya.

c. Dapat melihat informasi jarak dari jalur evakuasi dan posko pengungsian.

d. Dapat melihat letak posko pengungsian.

e. Dapat melihat jumlah pengungsi berdasarkan kecamatan.

f. Dapat melihat informasi mitigasi bencana.

g. Dapat melihat berita yang dikeluarkan oleh Badan Nasional Penanggulangan Bencana Daerah Banjarnegara

2. Administrator

a. Dapat mengatur data daerah rawan tanah longsor meliputi deskripsi, letak geografis dan tingkat kerawanannya.

b. Dapat mengatur data jalur evakuasi dan posko pengungsian.

c. Dapat mengatur data jumlah pengungsi.

d. Dapat mengatur halaman statis meliputi profil, visi dan misi dan struktur organisasi.

e. Dapat memberi peringatan apabila cuaca di suatu wilayah buruk.

3. Manajer

a. Dapat menerima laporan secara periodik terkait semua tanah longsor

b. Dapat melakukan kueri sesuai yang diinginkan 


\section{b. Perancangan Sistem}

Gambaran sistem dijelaskan dengan diagram konteks pada Gambar 2. Pada diagram konteks ini ada tiga entitas eksternal yaitu admin yang mengelola data tanah longsor, pengunjung yang dapat meminta informasi terkait tanah longsor, serta Kepala bappeda yang mendapat laporan dari sistem.

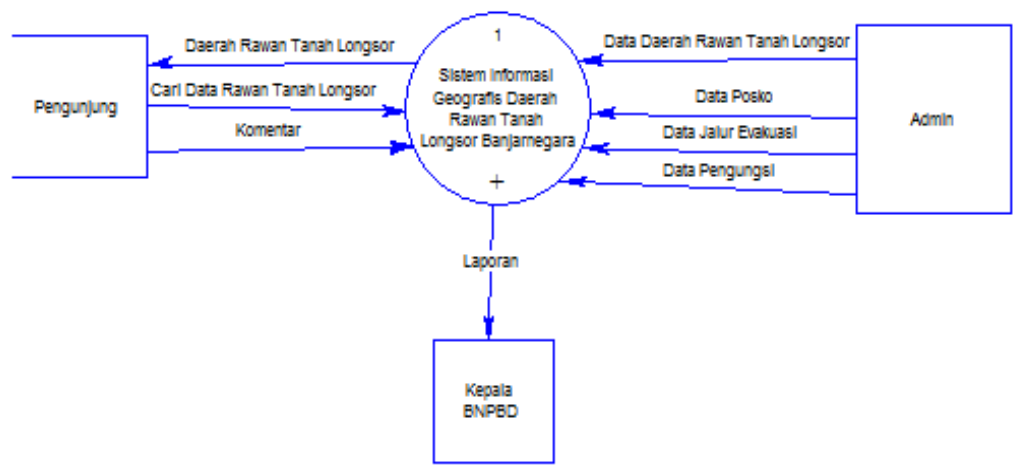

Gambar 2. Diagram konteks

Gambaran proses sistem dijelaskan dengan DAD level 1 pada Gambar 3. Pada level 1 ini berisi 4 proses utama yang ada dalam sistem.

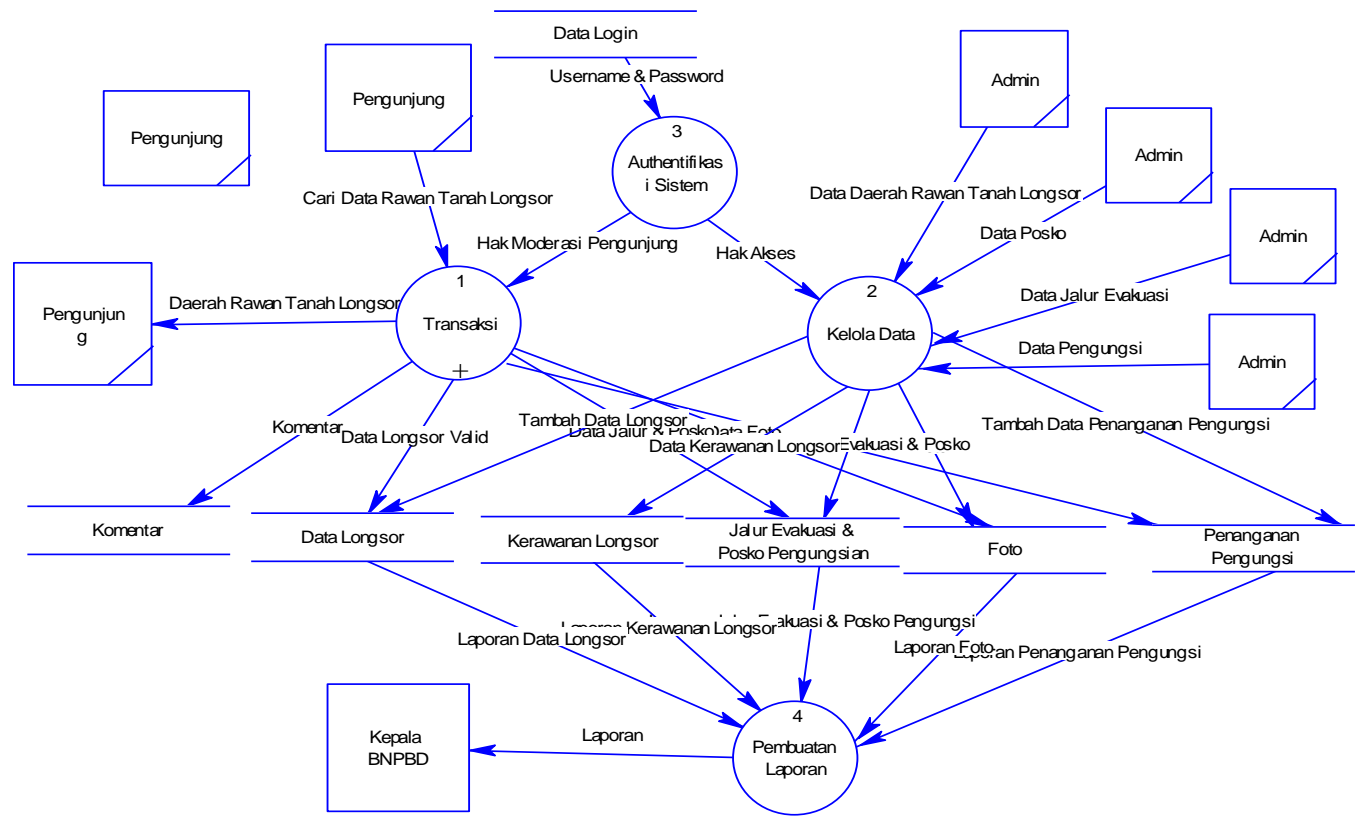

Gambar 3. DAD level 1

\section{c. Rancangan Prototipe Program}

Berikut beberapa tampilan rancangan prototipe program. Pertama kali muncul ada halaman utama yang terlihat pada Gambar 4 


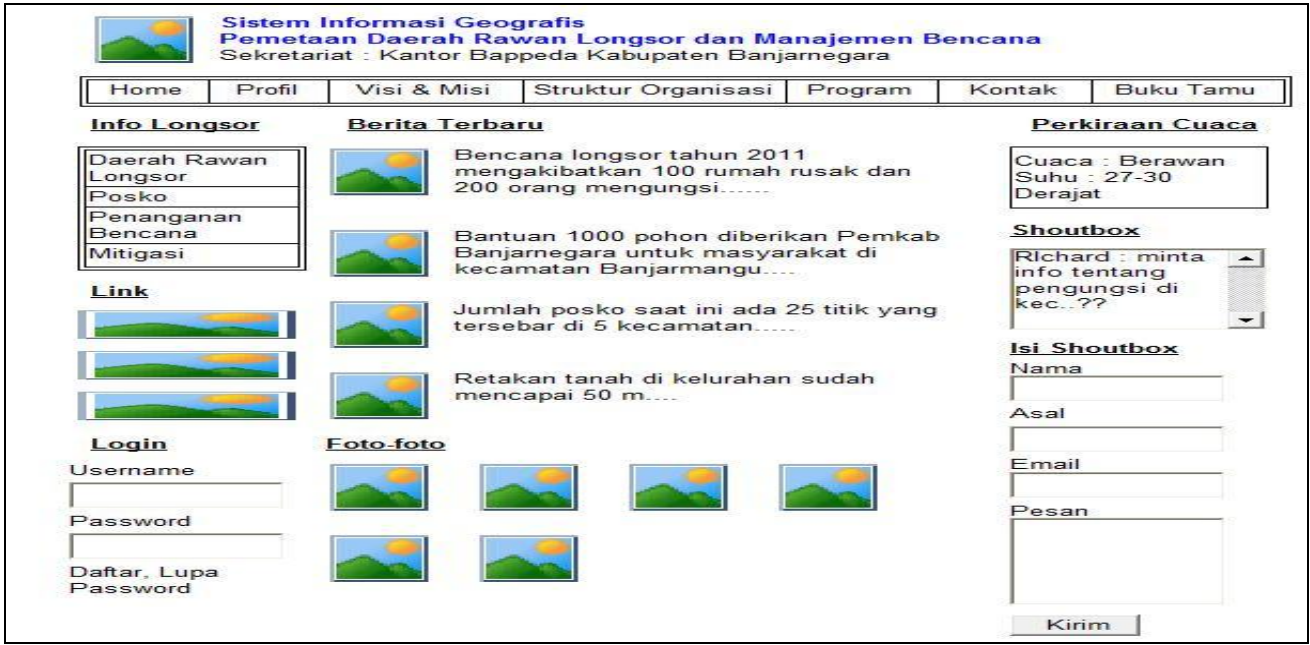

Gambar 4. Halaman Utama

Pada Halaman utama akan tampil judul aplikasi yang stake holdernya adalah Kantor Bappeda Kabupaten Banjarnegara. Kemudian sekilas ada menu terkait dengan informasi organisasi antara lain informasi Profil, Visi dan Misi, Struktur Organisasi, Program serta kontak yang bisa dihubungi dan buku tamu buat pengunjung. Tampilan awal ini juga menginformasikan berita terbafu terkait lingkunagn geogafis maupun tanah longsor, perkiraan cuaca dan shoutbox. Shoutbox bisa dikirim oleh setiap pengunjung dengan mengisikan nama dan email serta pesannya. Pengunjung bisa login untuk memilih ke menu berikunya atauapun mendaftar bila belum terdaftar sebagai anggota.

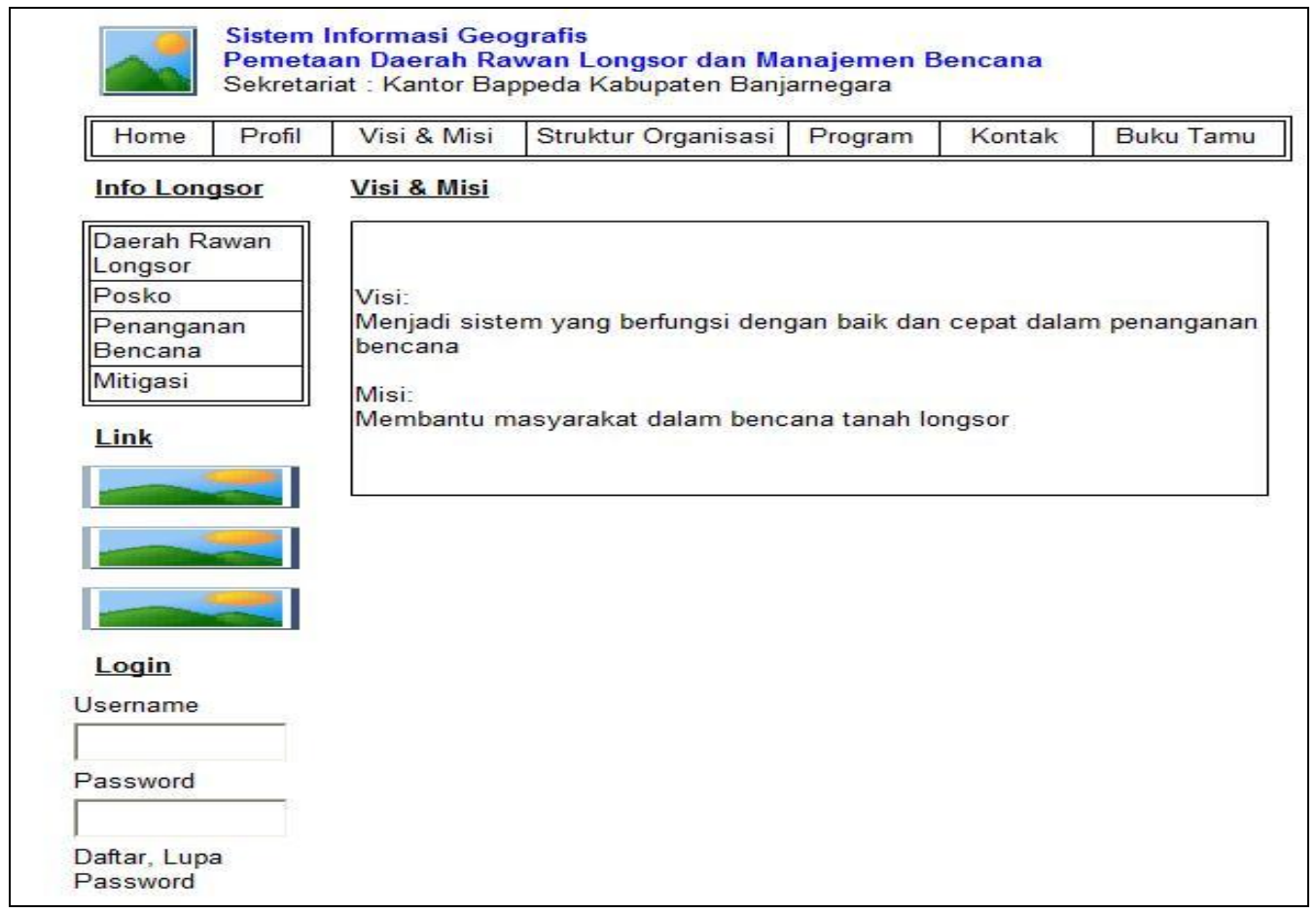

Gambar 5. Halaman Menu 
Halaman menu pada Gambar 5 merupakan kelanjutan dari halaman utama manakala dipilih menu yang sesuai.

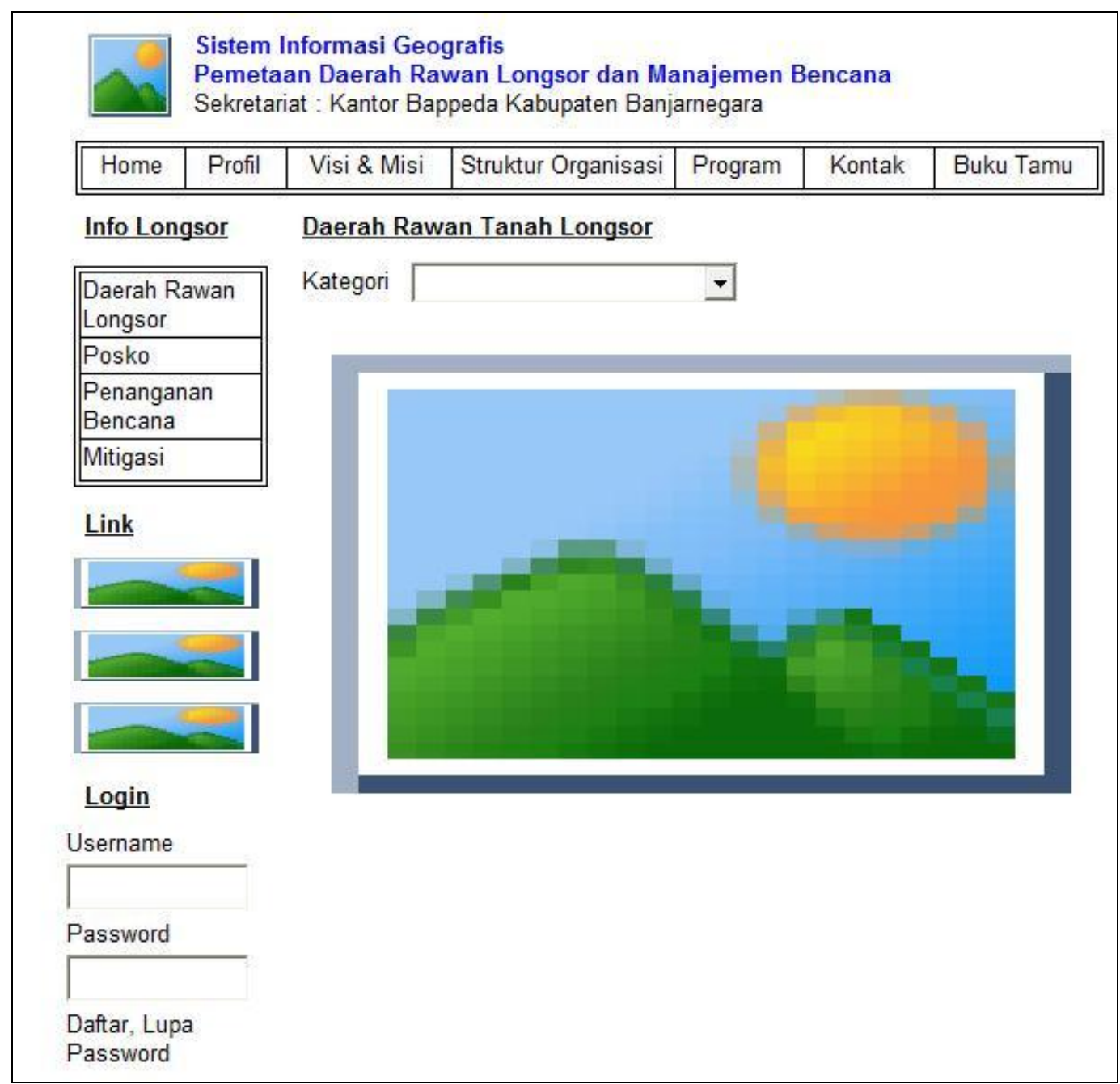

Gambar 6. Halaman Cari Lokasi Longsor

Pada Gambar 6 digunakan untuk melakukan pencarian lokasi tanah longsor dengan cara memilih kriteria tertentu yang sudah diberikan. Hasilnya akan ditampilkan peta geografisnya 


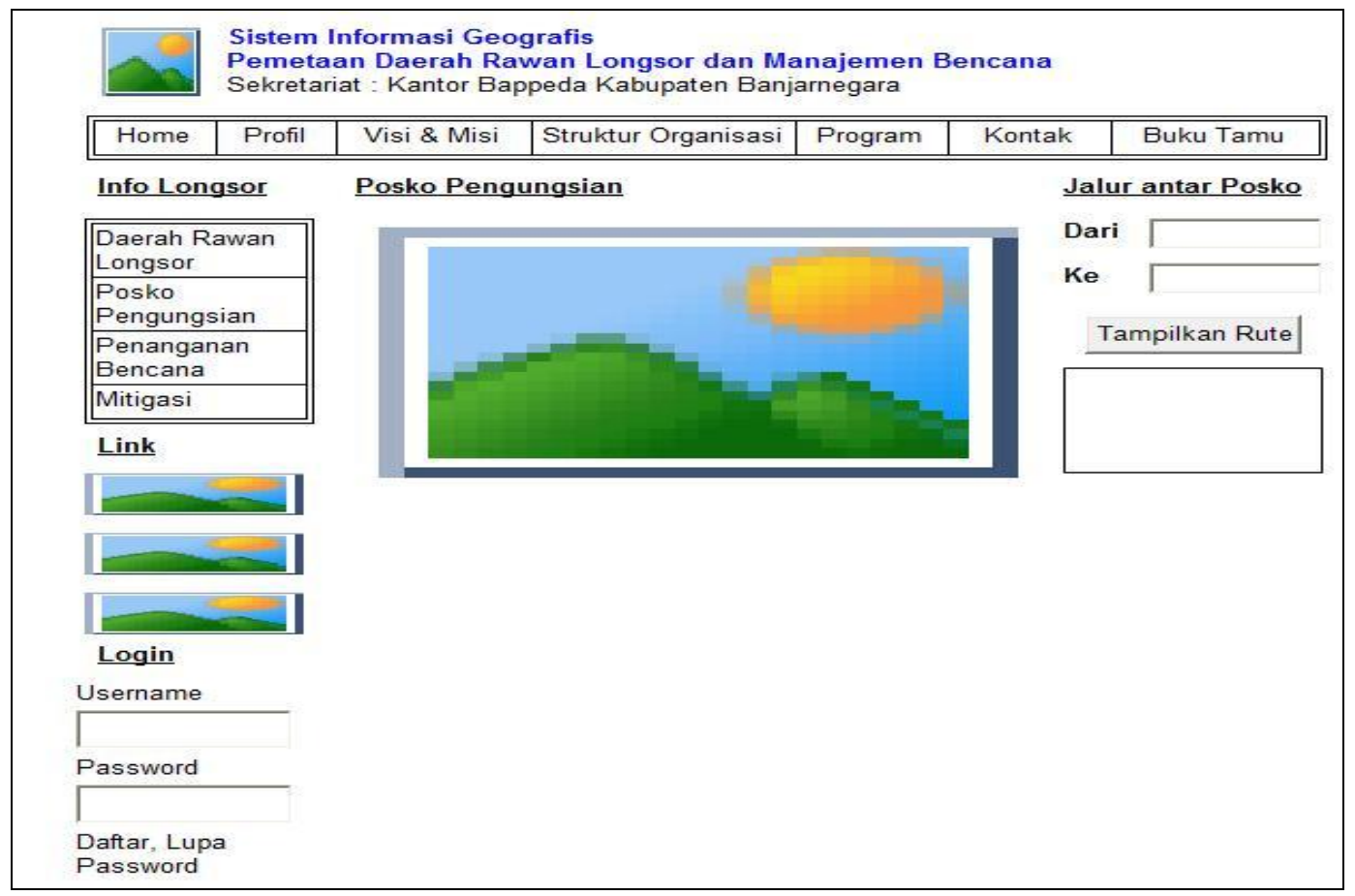

Gambar 7. Halaman Posko

Pada Gambar 7 akan ditampilkan peta posko pengungsian yang ada. Kemudian ada menu untuk mencari jalur antar posko dengan memasukkan posko asal dan posko tujuan serta akan menampilkan peta rutenya.

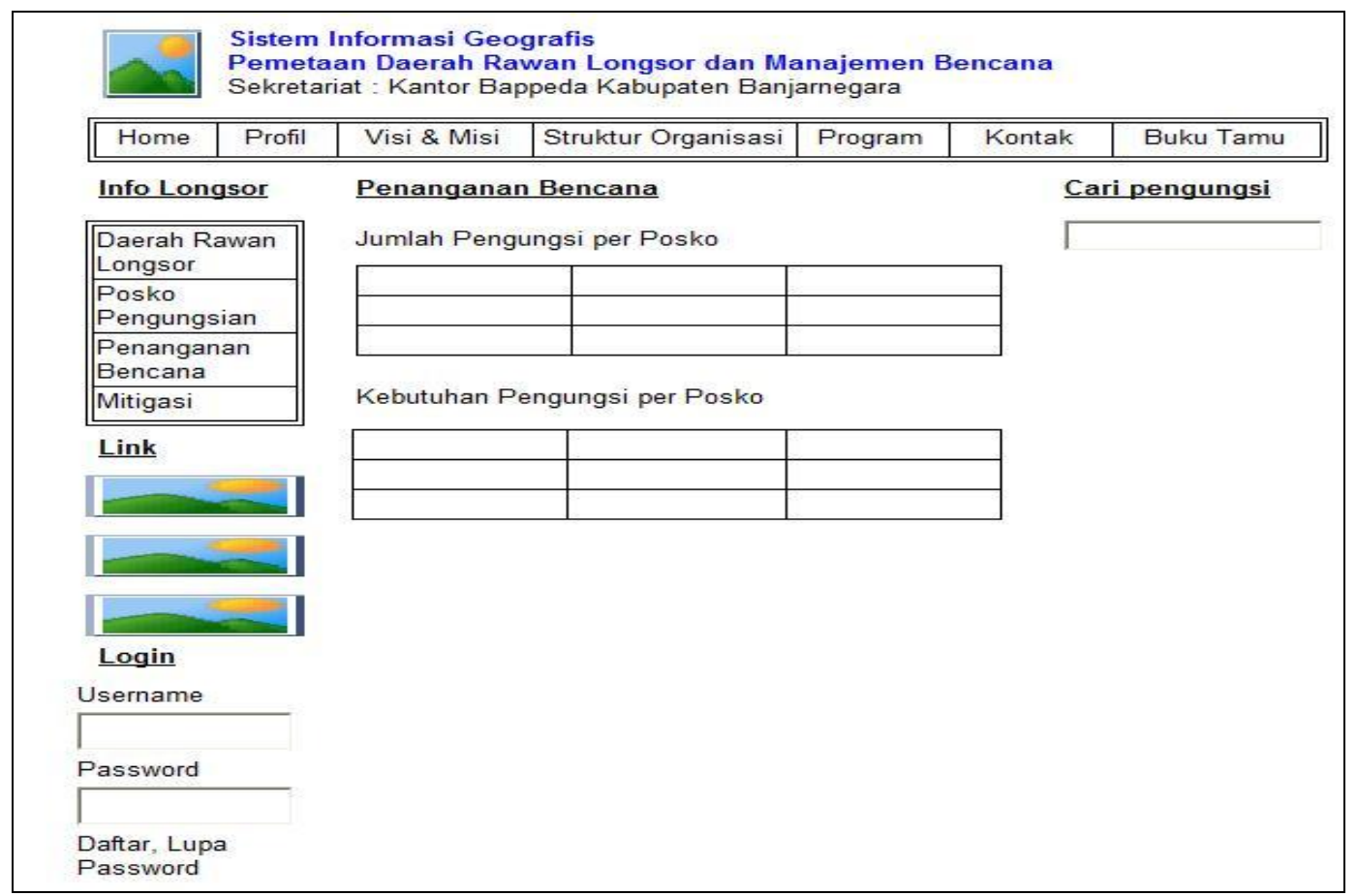

Gambar 8. Halaman Penanganan Bencana 
Pada Gambar 8 berupa halaman penanganan bencana akan menginformasikan jumlah pengungsian per posko, kebutuhan pengungsian per posko serta menu untuk mencari pengungsi dengan memasukkan namanya.

\section{SIMPULAN DAN SARAN}

\section{A. Simpulan}

Telah dirancang sistem geografis yang mampu memetakan daerahdaerah rawan longsor dan pengelolaan dalam manajemen bencana dengan baik, sehingga informasi dari sistem dapat dijadikan bahan pertimbangan dalam pengambilan kebijakan.

\section{B. Saran}

Hasil penelitian ini perlu dikembangkan lebih lanjut ke dalam implementasi program serta pengujian program sehingga nantinya dapat diterapkan di kabupaten Banjarnegara.

\section{DAFTAR PUSTAKA}

1. Tedy Setiadi, Jefree Fahana, Pengembangan Aplikasi Untuk Menentukan Daerah Pencemaran Limbah Home Industry Berbasis Sistem Informasi Geografis, Penelitian Dosen Muda 2010.

2. Prahasta, E., Konsep-Konsep Dasar Sistem Informasi Geografis, Informatika, Bandung, 2005.

3. Prahasta, E., Sistem Informasi Geografis : ArcView Lanjut Pemrograman Bahasa Script Avenue, Informatika, Bandung, 2004.

4. http://lppm.uns.ac.id/2010/04/21/mitigasi-dan-manajemen-bencana-alam-tanahlongsor-di-daerah-pedesaan-kabupaten-karanganyar/, Tanggal 28 Maret 2011 Jam 14.30 WIB

5. http://decib.wordpress.com/2009/03/14/sekilas-mitigasi-bencana-longsor, Tanggal 28 Maret 2011 Jam 14.30 WIB

6. http://www.ppk-depkes.org/info-bencana/data-bencana.html, 5 April 2011 Jam 19.00 WIB 